\title{
Integrated multi-resource planning and scheduling in engineering project
}

\author{
Samer Ben Issa ${ }^{a}$ and Yiliu Tu ${ }^{a^{*}}$
}

${ }^{a}$ SCHULICH School of Engineering, Department of Mechanical and Manufacturing Engineering, University of Calgary, 2500 University Dr., NW, Calgary, Alberta T2N 1N4, Canada

\begin{tabular}{|c|c|}
\hline CH R O N I C L E & A B S T R A C T \\
\hline $\begin{array}{l}\text { Article history: } \\
\text { Received: March 5, } 2017 \\
\text { Received in revised format: May } \\
16,2017 \\
\text { Accepted: July } 24,2017 \\
\text { Available online: } \\
\text { May 24, } 2017 \\
\text { Keywords: } \\
\text { Integrated planning and schedul- } \\
\text { ing process } \\
\text { Resource constrained project }\end{array}$ & $\begin{array}{l}\text { Planning and scheduling processes in project management are carried out sequentially in prac- } \\
\text { tice, i.e. planning project activities first without visibility of resource limitation, and then sched- } \\
\text { uling the project according to these pre-planned activities. This is a need to integrate these two } \\
\text { processes. In this paper, we use Branch and Bound approach for generating all the feasible and } \\
\text { non-feasible project schedules with/without activity splitting, and with a new criterion called } \\
\text { "the Minimum Moments of Resources Required around X-Y axes (MMORR)", we select the } \\
\text { best feasible project schedule to integrate plan processing and schedule processing for engineer- } \\
\text { ing projects. The results illustrate that this integrated approach can effectively select the best } \\
\text { feasible project schedule among alternatives, improves the resource utilization, and shortens the } \\
\text { project lead time. }\end{array}$ \\
\hline
\end{tabular}

\section{Introduction}

Planning and scheduling are two important decision-making processes which aim at gaining high utilization of resources and improving the efficiency of the project through the project life cycle. However, in practice, project planning, which mainly deals with activity plan, is carried out independently from the project scheduling which determines the time frames and available resources for these activities. Generally, project planners produce a complete set of activities for achieving a set of objectives and then passes them to the schedulers for time and resource assignment. On the other hand, not all generated plans by planning department will be schedulable, depending on resource availabilities. Some activities may not executable within satisfactory time frames or likewise some activities may need to be splitting in certain time to achieve shorter project lead time and resource feasibility. Poor integration between planning and scheduling processes results in infeasible project plan or/and schedule, low resource utilization, project delays and overrun project budget. In practice, a huge gap between the planning process and scheduling exists as illustrated in Fig. 1. This gap has two severe drawbacks:

* Corresponding author.

E-mail address: paultu@ucalgary.ca (Y. Tu) 
1. The two processes work in an independently way without using common criteria.

2. The outputs of planning phase may not be feasible in the scheduling phase since some planned activities may not be executable due to resource limitation constraints or some other constraints. On the hand, the pre-planned activities may obstacle the project schedule to be optimal or rational. This often results in forwards and backwards planning and scheduling work overload and hence poor project schedule and low project resource utilization efficiency.

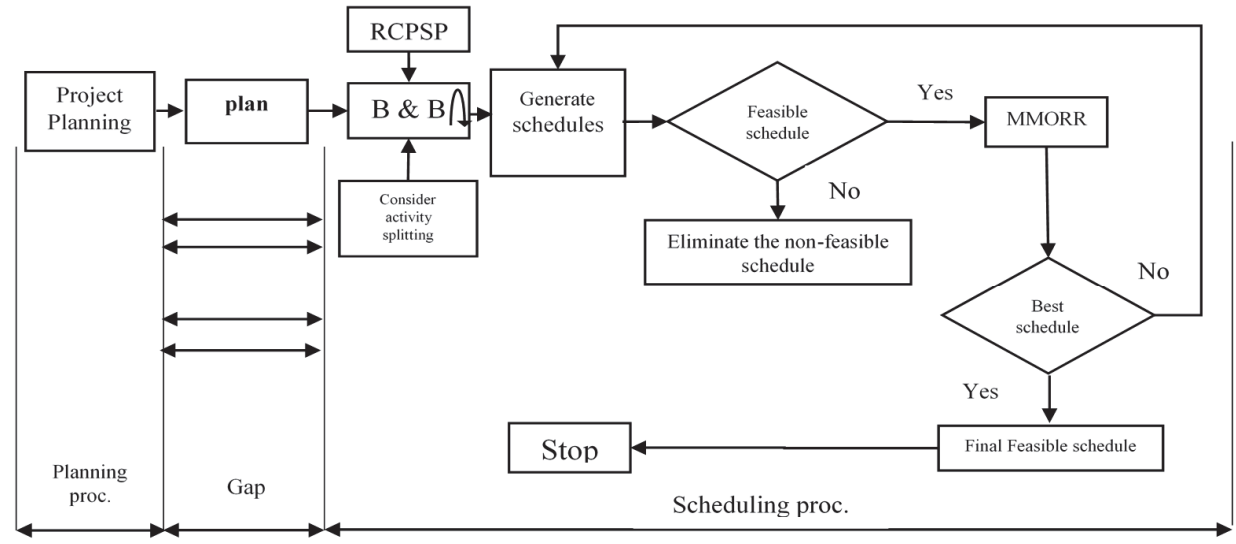

Fig. 1. The gap between project planning and scheduling.

The Resource Constrained Project Scheduling Problems (RCPSP) has been widely studied. A fundamental assumption is that project activities in progress cannot be split after they have been planned. On the other hand, the two common methods employed in project scheduling are program evaluation and review technique (PERT) and critical path method (CPM) which implicitly assume that resources availability is unlimited and it would never be binding on scheduling decision. However, in practice, the resource availability is always a problem which delays activities even if all the preceding activities are finished. In other words, each activity in a project can be started not only when all the precedence constraints are satisfied, but also the required resources are available for the time when the activity starts and completes. Although there is a strong relationship between planning and scheduling processes, the integration of them is still a challenge. The integration of these two decision-making processes can achieve a significant improvement of the resource utilization and reduction the project lead time and the cost, especially if considering the activities splitting as one of the ways that increase the improvement in the efficiency of the resource utilization. In this paper, we present a Branch and Bound method based approach to integrating the planning and scheduling processes in project management as indicated in Fig. 2., which is capable of generating alternative schedules based on the idea of interactively and concurrently planning activities and scheduling project. To do this, we assume that some of the activities can be split into two or more sub-activities which can be scheduled independently. To split planned activities, we expect an improvement of resource utilization and hence reduction of the project lead time. In short, the contributions of this paper are:

1. Integrating planning and scheduling processes in project management through reasonably splitting planned activities.

2. Developing a new criterion so-called Minimum Moment of Resources Required around X-Y axes (MMORR) to effectively measure and minimize the resource idle times.

3. A new heuristic for how to split activities have been used in case the resources to execute activities had violated.

Through the case study, it demonstrates that the project lead time is reduced and the average resource utilization is improved. 


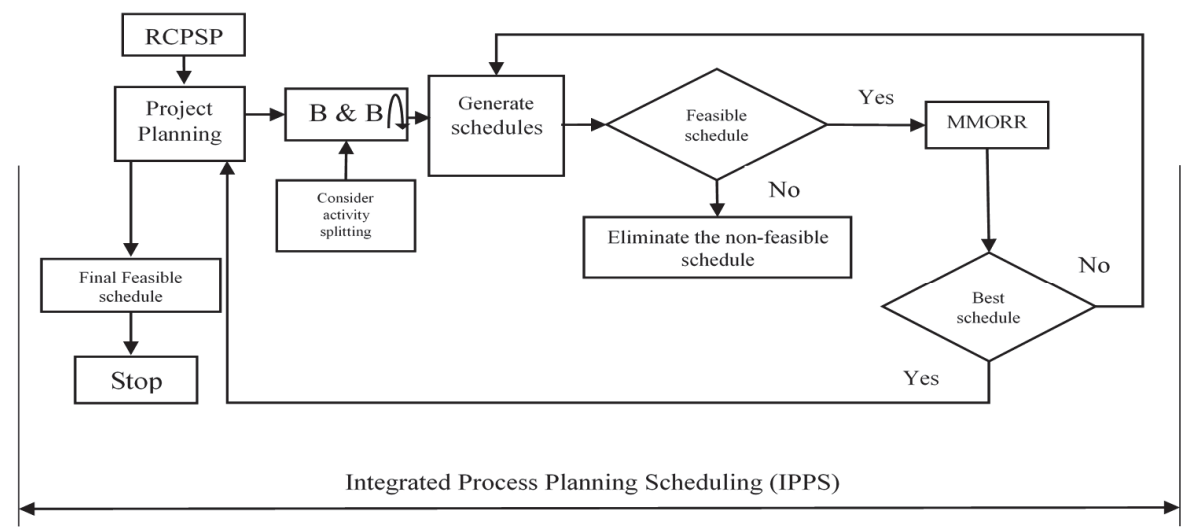

Fig. 2. The proposed model for integration process planning and scheduling.

\section{Literature review}

RCPSPs are non-deterministic polynomial-time hard (NP-hard) problems and their solutions cannot be obtained analytically, thus numerical methods or heuristics and meta-heuristics are used to obtain rational solutions. In the following, we will review the papers which are relevant to the problem addressed by this paper. The minimum moment approach (Harris 1978) is one of the several approaches used to resolve resource leveling without activity splitting. The method levels the resources by using the float free time for the non-critical activities, and assume limit project duration and unlimited resources. Later Hiyassat (2000) develops Harris' method by considering the value of activity's free float time and its resource rate for how to select the activity that will be shifted to the new position. Hiyassat (2001) extends the modification of the previous method (Hiyassat 2000) and applies to network with multi resources under the same conditions. However, in some cases, the results are better than those traditional methods. Ease (1989) proposes an integer linear optimization model for resource allocation problem. Elmegraby (1993) formulates a dynamic programming heuristic to solve the problem. Hegazy (1999) addresses the resource leveling and allocation problem using genetic algorithm to minimize the moment of the resource profile around the horizontal axis, but without considering activity splitting possibilities. Symeon et al. (2009) use the entropy maximization method to revisit the minimum moment method for resource leveling. Son and Mattila (2004) present a new method using binary programming, which the splitting activity is allowed. Exact method of optimization could be only efficient for solving small problems with very few activities. Doulabi et al. (2011) develop genetic algorithm based heuristic for resource leveling in large scale projects, and assume that the set of activities that may be split is known in advance and the project makespan (or lead time) is determined by the CPM should be fixed. Karra and Naser (1986) present a mixed integer linear programming model for the management of resources. The model derives the schedule for equipment rental and transient resources and can be used as an estimating method for multi-project resource planning and sharing. Burns et al. (1996) present an algorithm using integer linear programming to efficiently obtain optimal resource selection that optimizes time/cost of construction project. Feng et al. (1997) present a genetic algorithm based heuristic for construction Time-cost trad-off optimization. They illustrate that the activity can be completed by other ways with the corresponding cost and time. Hariga and El-Sayegh (2011) present an optimization model for resource leveling that allows activity splitting and minimizes the extra cost of acquiring and releasing resources. El-Rayes and Dho (2009) present the development of two innovative resource leveling metrics to directly measure and minimize the negative impact of resource fluctuation. There are available models introduced and used to reduce resource fluctuation by using some other methods, such as:

- Sum of square method (Burgess \& Killebrew, 1962; Ahuja, 1976; Bendelloni, 1994; Hegazy, 1999; Son \& Skibiniewski, 1999).

- $\quad$ Sum of square of resource changing (Ahuja, 1976). 
- Deviation between actual resource usage and resource availability (Easa, 1989; Chan, 1996; Chua, 1996; Mattia \& Abraham, 1998; Leu \& Yang, 1999; Akpan, 2000; Son \& Mattia, 2004).

- Absolute difference between resource usages during consecutive time period (Easa, 1989; Senuuci \& Adeli, 2001; Senouci \& Eldin, 2004).

Michel and Fayez (2004) present a new Tabu search algorithm. It investigates the efficiency of a neighborhood structure based on activity sequences where the precedence constraints are maintained. Shanmuganayagam (1989) proposes the current float model to allocate limited resources by given priority to the activities that have the least current float for finding feasible solution. Colin and kwangho (1990) present a new method, named "A* search", for finding a minimum makespan schedule for a multi-resource constrained project scheduling problem. Karen and Stephen (1999) highlight a series of models for integration planning and scheduling technologies and illustrate their merits and drawbacks. Lee and Kim (2001) propose an approach for the integration of planning and scheduling using simulation based genetic algorithm.

In short, the activity splitting to support interactively and currently planning activities and scheduling the project has not been meaningfully found in literature.

\section{Problem Definition}

In this paper, after generating the first project plan to schedule activities based on their impact around $\mathrm{X}-\mathrm{Y}$ axes subject to precedence and resources constraints, the problem can be illustrated as follow:

\subsection{Objective function}

The best sequence to perform project activities has been determined by using the branch and bound method with MMORR, which minimizes the total minimum moments of resources required around axes, as aforementioned. Leveling limited resources prevent the excessive of the resource fluctuation, minimizes idleness in resources and reduces the cost. The objective function of this problem is to reduce the total of the moment of the resources required around X-Y axes to achieve all the other objectives.

\subsection{Problem Assumption}

$N+2$ are project activities related by a set of finish-start relationships with a time lag $=0$, where each activity must be processed without violating the precedence relations among them to complete the project. The activities $I=(0,1,2, \ldots n+1)$ have a constant duration for executing them denoted by $d_{i}$. Activities 0 and $n+1$ are dummy and their durations are assumed $d_{(0, n+1)}=0$, which represent the initial and final project activity. Each activity $i$ requires a renewable resource type $K=(1,2, \ldots . h)$. The resources have limited capacity at any time of the project life cycle, and should be assigned on activities. The maximum resource availability $\mathrm{K}$ in each period is $R_{k}$. Activity $i$ requires $r_{i k}$ units of resource type $K$ during its duration of execution $d_{i}$. The factors $r_{i k}, d_{i}$ and $R_{k}$ are assumed to be deterministic and $r_{0 k}=r_{(n+1) k}=0$

\subsection{Constraints}

Precedence relationships, among activities, and limited resources are two types of constraints that must not be violated throughout project life cycle.

\subsection{Notation}

The following symbols are used in this paper: 
$d_{i}$ - duration of activities.

$E s_{i}$ - earliest start time for activities.

$E f_{i}$ - earliest finish time for activities.

$K$ - number of resources to execute activities.

$M$ - the total moment of $M_{x} \& M_{y}$.

$M_{x}$ - the moment of $r_{i k}$ around $\mathrm{X}$ - axis

$M_{y}$ - the moment of $\left(r_{i k} * d_{i}\right)$ around Y-axis

$n$ - number of activities $i$.

$r_{i k}$ - the resource type $K$ required to execute activity $i$.

$R_{k}$ - maximum availability of resource $K$

$S_{t}$ - number of feasible and non-feasible project schedule at any time ( $\mathrm{t}$ ) when the resource conflict is happened.

$T$ - project duration.

$x_{i t}=\left\{\begin{array}{l}1 \text { in case the activity is splitting } \\ 0 \text { otherwise }\end{array}\right.$

$y_{i t}=\left\{\begin{array}{l}1 \text { in case the activity is ongoing } \\ 0 \text { otherwise }\end{array}\right.$

$y_{i t}, x_{i t}$ cannot get the value 1 simultaneously.

\section{The proposed model}

The proposed model, in this study, can be illustrated as follow:

$$
\begin{aligned}
& \min z=\sqrt{\left(M_{x}\right)^{2}+\left(M_{y}\right)^{2}} \\
& \left(M_{x}\right)^{2}=\left(\sum_{k=1}^{h} \sum_{t=1}^{T}\left(r_{i t} / R_{k}\right)^{*} r_{i t}\right)^{2} \\
& \left(M_{y}\right)^{2}=\left(\sum_{k=1}^{h} \sum_{t=E S_{i}}^{E f_{i}}\left(r_{i t} / R_{k}\right)^{*}\left(d_{i}\right)^{*} E s_{i}\right)^{2}
\end{aligned}
$$

Subject to:

$$
\begin{aligned}
& \sum y_{i t}>0 \quad \text { when } \quad i=1 \\
& \sum_{t=E s_{i}}^{E f_{i}} y_{i t}=d_{i} \quad \forall i=0,1,2, \ldots . n+1 \\
& E f_{i(\text { pred })}<E f_{i(\text { succ })}-d_{i(\text { succ })} \quad \forall i=0,1,2, \ldots . n+1
\end{aligned}
$$




$$
\begin{aligned}
& \sum_{t=1}^{T} \sum_{i=1}^{n+1} r_{i k} y_{i t} \leq R_{k} \quad K=1,2, \ldots . h \\
& y_{i t}, x_{i t}=\{1,0\} \\
& S_{t}=2^{n}-1 \quad \forall t=1, \ldots . T \quad n=\sum i
\end{aligned}
$$

Eq. (1) presents the objective function that minimizes the moment of resources required around X-Y axes. Eqs. (2-3) present the calculations of the moment of resources required around axes. Constraint set (4), ensure that at least one activity should be scheduled on the first day. Constraint set (5), guarantees that for each activity is in progress for duration time units. Constraint set (6), specifies the precedence constraint (no activity can be started until all their predecessor activities are finished). Constraint (7), specifies the resource constraint (resource utilization throughout any time must not exceed the resource availability for any resource type). Constraint set (8), ensures that the variables are integers. Eq. (9), illustrates a number of ways to perform project activities, whether feasible or non-feasible activities schedules, which schedulers can get at any time when the resources conflict occurs.

\section{Methodology}

\subsection{Branch and Bound Method to generate project schedules:}

A Branch and Bound method based approach was suggested by Joel P. Stinson (1976-1978) to solve Resource constrained project scheduling problems without considering splitting activities. Let's assume that, the project network indicated in Fig. 3 has activities A1, A2, B1, B2, C1, C2, D1, and D2 and the activity properties are indicated in Table 1 (the resources available R1, R2 and R3 equal 1,1 and 1 respectively):

Table 1

Activity properties for the given problem

\begin{tabular}{ccccccccccc}
\hline Activity & Duration & Es & Ef & Ls & Lf & S & R1 & R2 & R3 \\
\hline A1 & 15 & 0 & 15 & 16 & 31 & 16 & 1 & 0 & 0 \\
A2 & 20 & 15 & 35 & 31 & 51 & 16 & 0 & 1 & 0 \\
B1 & 10 & 0 & 10 & 11 & 21 & 11 & 1 & 0 & 0 \\
B2 & 30 & 10 & 40 & 21 & 51 & 11 & 0 & 1 & 0 \\
C1 & 27 & 0 & 27 & 0 & 27 & 0 & 1 & 0 & 0 \\
C2 & 30 & 27 & 57 & 27 & 57 & 0 & 0 & 1 & 0 \\
D1 & 24 & 40 & 64 & 51 & 75 & 11 & 0 & 0 & 1 \\
D2 & 18 & 57 & 75 & 57 & 75 & 0 & 0 & 0 & 1 \\
\hline
\end{tabular}

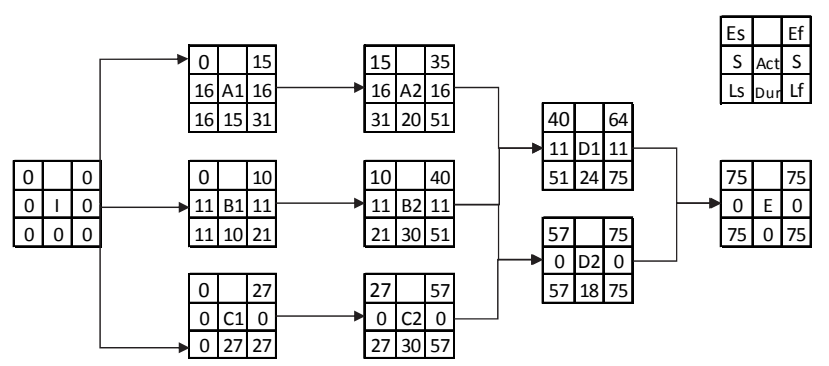

Fig. 3. Project network for problem given.

We present a Branch and Bound algorithm based approach as follows, which allows splitting project activities: 
- Find a number of ways to perform project activities, regardless of feasible or non-feasible, when resources conflict occurs at a certain time by applying equation (9), $s=2^{n}-1$, as depicted in Fig. 4a and Fig. 4b at stages (1) and (2) respectively based on the resources constrain where $n$ is the number of the activities at that time.

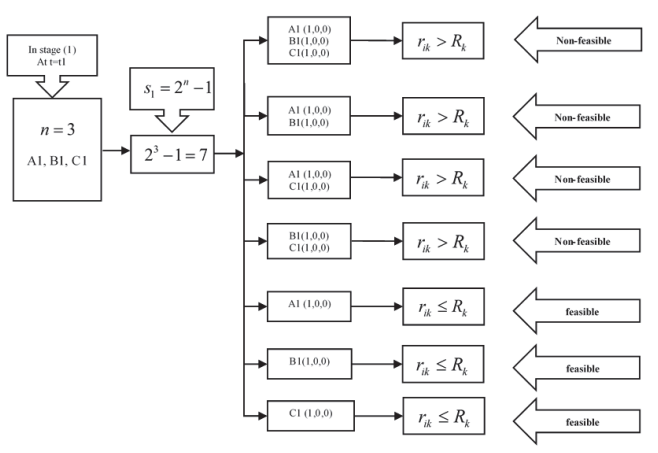

Fig. 4a. The ways to execute project activities at stage (1)

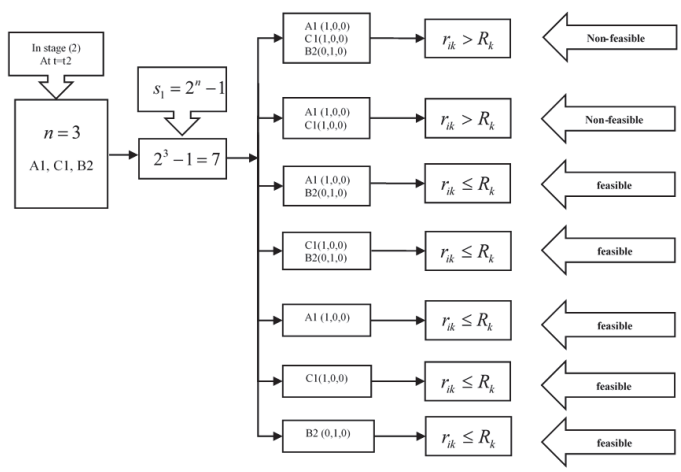

Fig. $\mathbf{4 b}$. The ways to execute project activities at stage (2)

After finding all the ways to execute the activities at any time when the resources conflict occurs, we can draw all the feasible and non-feasible project schedules in the project schedule tree as illustrated in Fig. 5.

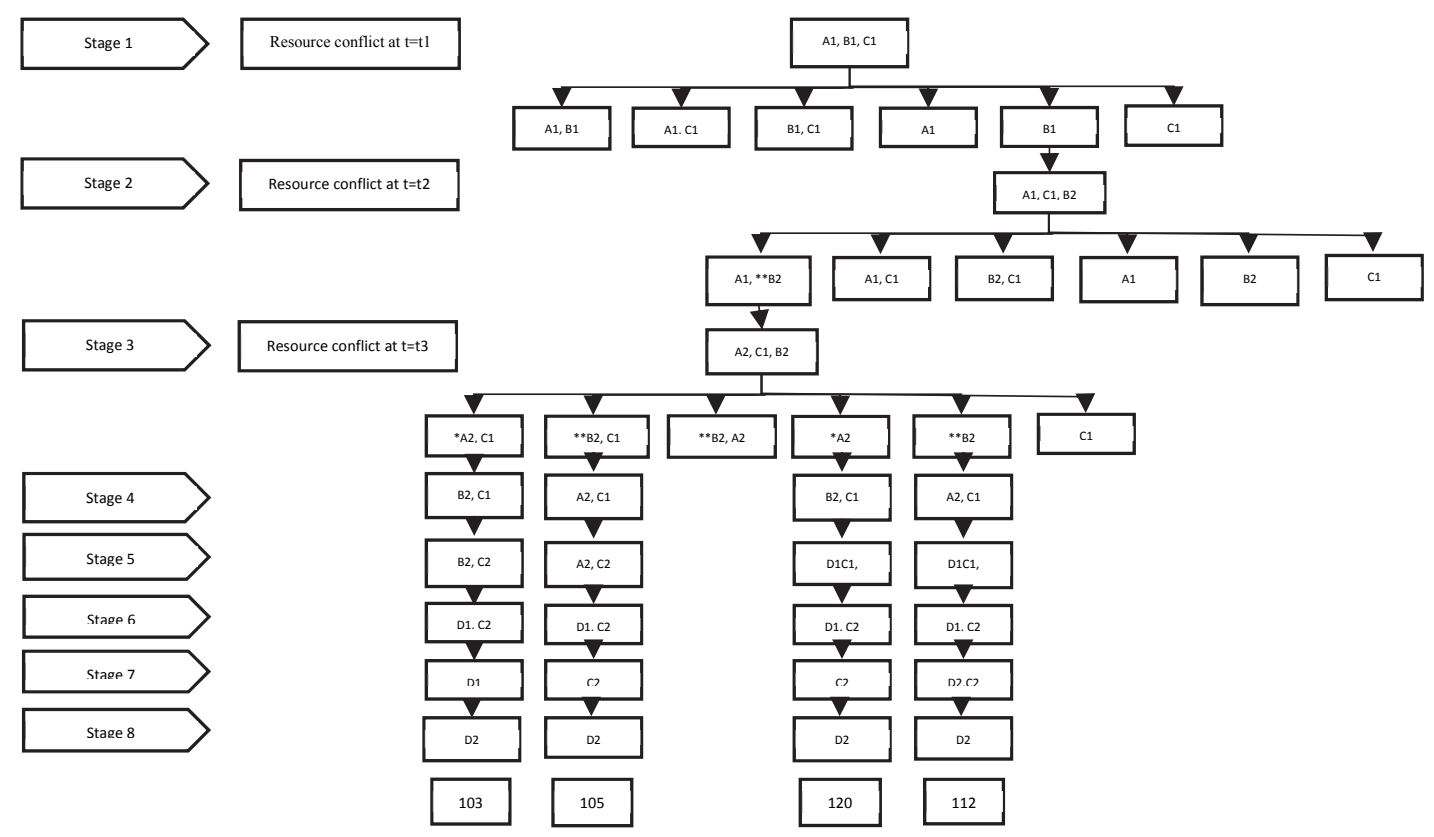

Fig. 5. Project schedule tree

- The model will eliminate all non-feasible activity schedules which cannot meet constraint (7) at any stage and works only with the feasible activity schedules, which need the largest amount of resource to avoid the maximum moment around the axes.

- The model will not consider whether the project activities in the previous stage are ongoing or not, based on the assumption which allows splitting the activity at any time. Thereby, there is no doubt that the splitting activities process will be one of the ways which will help to get feasible project schedules, which is critical to solving the problem. It may be noted that activities A2 and C1, which are indicated by $\left(^{*}\right)$ in stage 3 in Fig. 5, have not been ongoing in stage 2. Similarly, activity B2, which is indicated by $(* *)$ in stage 2 , has been interrupted and cannot 
ongoing in stage 3. That means there is splitting in activity B2 happened in the end of stage 2 while the other activities $\mathrm{A} 2 \& \mathrm{C} 1$ start in stage 3 , which will shorten the project duration from 105 to 103 days.

- The proposed model will assume that the completion time is $\mathrm{T}=\mathrm{M}$ and the value of the objective function is $\mathrm{Z}=\mathrm{N}$, where $\mathrm{M}$ and $\mathrm{N}$ are large numbers.

- To get the best feasible schedule to perform project activities, the proposed model repeats the same procedures in each stage for each feasible activity schedules and compares the result which has been obtained with the previous result and keeps the better one by using (MMORR).

For activities A1, B1 and C1 in stage (1) as illustrated in Fig. 1, their requirements of the resources are $r_{A 1(1,0,0)}, r_{B 1(1,0,0)}$ and $r_{C 1(1,0,0)}$ respectively. Check if there are any resources conflict because of the scarcity $\left(r_{A 1(1,0,0)}+r_{B 1(1,0,0)}+r_{C 1(1,0,0)}>R_{K(1,0,0)}\right)$. In case if there is a conflict, find all the ways to perform the project activities without considering whether they are feasible or non-feasible at that stage by using equation (9). The number of feasible and non-feasible activity schedules are calculated as 7 . After eliminating all non-feasible activity schedules, the model will start with the first feasible activity schedule obtained from stage (1) which needs the biggest value of the resources to provide the minimum moment around the axes. For stage (2), the constraints should be checked after activity B1 finishes and activity B2 starts. If constraint (7) is not achievable, follow the same procedure in stage (1) to find $S$ (there are 3 activities in stage (2), this means the number of the ways to execute the activities, without considering whether the ways are feasible or non-feasible, equals 7). The number of the feasible and non-feasible activity schedules in stages (1) and (2) equals $7 * 7=49$. After activity A1 has finished and activity A2 starts in stage (3), the number of feasible and non-feasible activity schedules equals 7. Thereby, to perform all the activities in stages (1), (2) and (3), there are $7 * 7 * 7=343$ schedules, which have differences in activity sequences. The number of all the feasible and non-feasible project schedules, which can execute the entire project activities, with/without splitting activity is $S=$ $S_{t=1} * S_{t=2} * S_{t=3} * \ldots . S_{t=T}$.

\subsection{Minimum Moment of Recourses Required (MMORR) to find the best schedule:}

Assume there is a small project which consists of 5 activities A, B, C, D and E. The feasible project schedule after resource leveling is shown in Fig. 6.

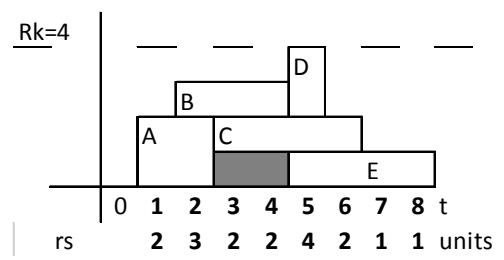

Fig. 6. Resource histogram (feasible project schedule)

To evaluate the feasible project schedules obtained from the previous step, and select the best one:

- First, apply Eq. (2) to calculate the value of the moment $M_{x}$ of the resources required around $\mathrm{X}$ axis as a resource constraint, by converting the resource histogram (feasible project schedule) after resources leveling to moment histogram as shown in Fig. 7.

- Second, apply Eq. (3) to calculate the moment $M_{y}$ of the resource required around Y axis as a precedence constraint, by converting the resource histogram (feasible project schedule) after 
resources leveling, based on the earliest start time of the activity, to moment histogram as shown in Fig. 8.

- Finally, find the value of the objective function, by applying Eq. (1) for $\sum M_{x}$ and $\sum M_{y}$ as illustrated in Fig. 9.
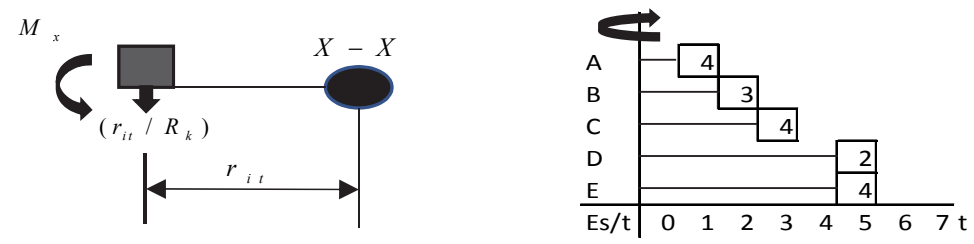

Fig. 7. Moment histogram (X-axis)

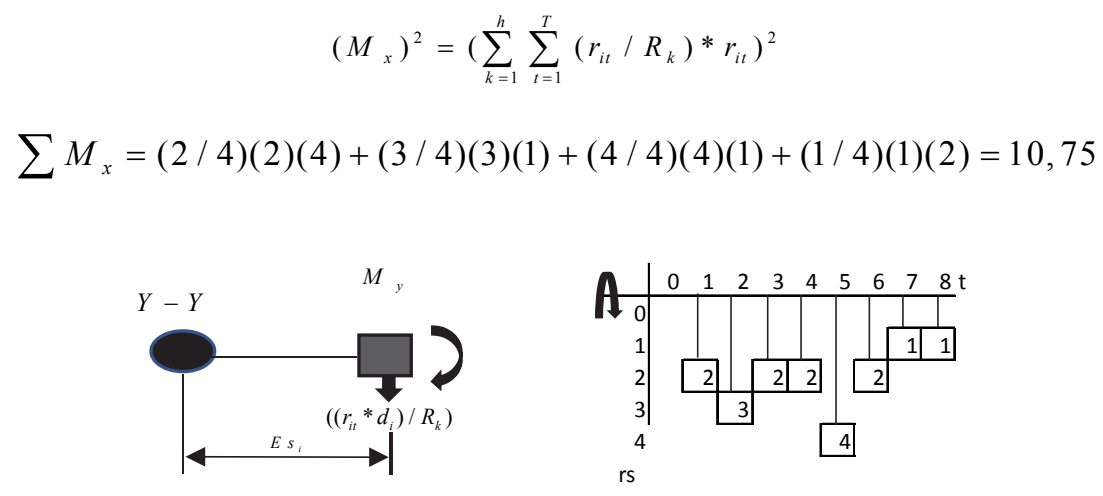

Fig. 8. Moment histogram (Y-axis)

$\left(M_{y}\right)^{2}=\left(\sum_{k=1}^{h} \sum_{t=E s_{i}}^{E f_{i}}\left(r_{i t} / R_{k}\right)^{*}\left(d_{i}\right)^{*} E s_{i}\right)^{2}$

$\sum M_{y}=(2 / 2)(2)(1)+(1 / 2)(3)(2)+(2 / 4)(1)(5)+(1 / 4)(4)(5)=13$

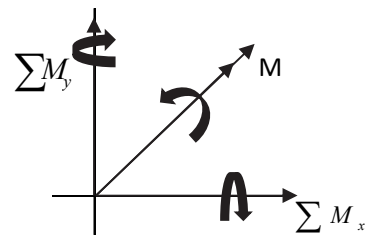

Fig. 9. Moments result

$$
\min z=\sum M=\sqrt{\sum M_{x}^{2}+\sum M_{y}^{2}}=\sqrt{10,75^{2}+13^{2}}=16.87
$$

let us explain how the (MMORR) effects on the decision-making for the project if there are several schedules for performing project activities, which has the same completion time but with different activity sequences as indicated below:

A small project consists of 5 activities A, B, C, D and E and the activity properties are indicated in Fig. 10. The project schedule, before resource leveling, is indicted in Fig. 11: 


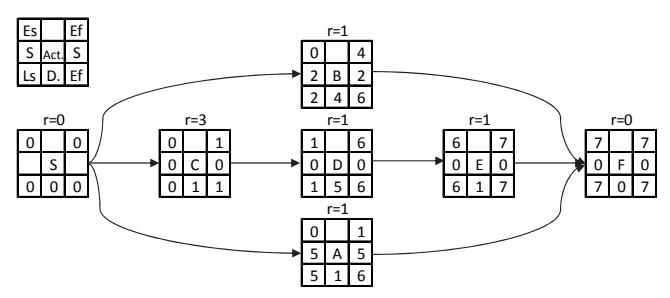

Fig. 10. Project network

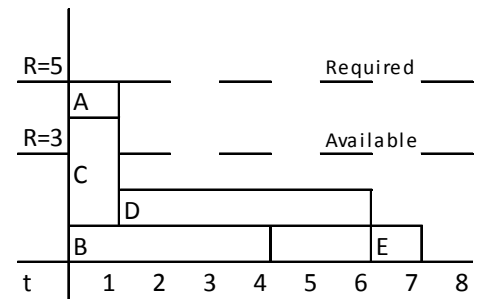

Fig. 11. Project schedule before resource leveling

After using the proposed model, we can obtain several feasible project schedules, as indicated in Figs. 12(a, b, c, d, e, f, and g), to complete the project. These schedules are equal in the project completion time 7 days.

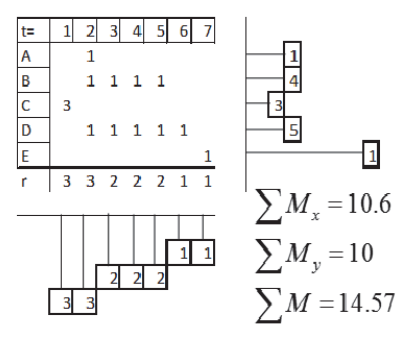

Fig. 12a.

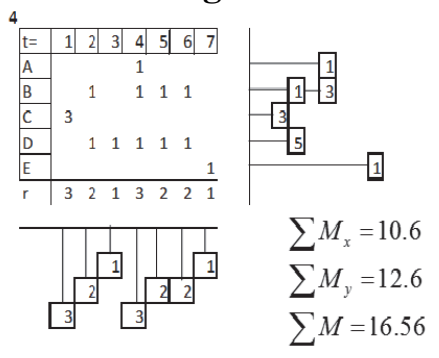

Fig. 12d.

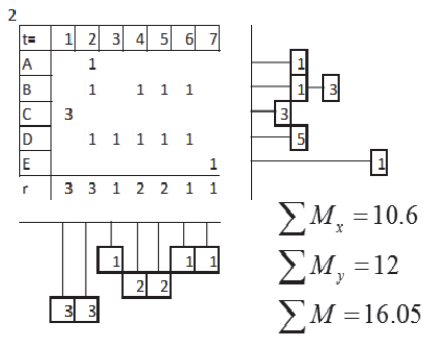

Fig. 12b.

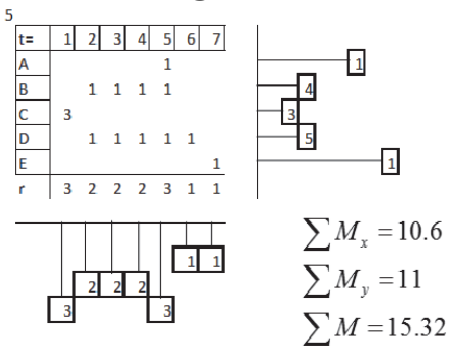

Fig. 12e.

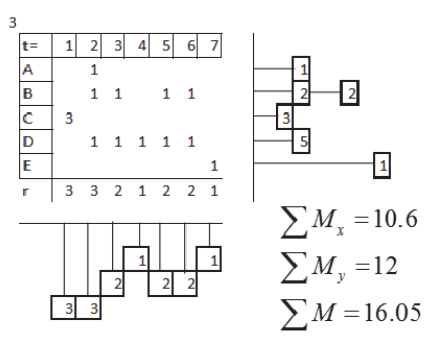

Fig. 12c.

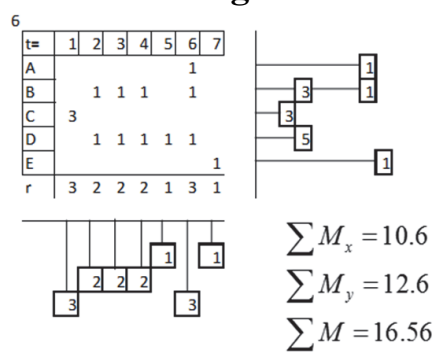

Fig. 12f.

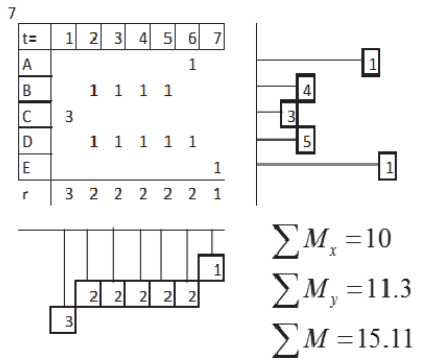

Fig. 12g

It can be seen from Figs. 12(a, b, c, d, e, f and g) that the lowest value of $\sum M_{x}$, i.e. 10, is obtained in Fig. 12g, and the lowest value of $\sum M_{y}$, i.e. 10, is obtained in Fig. 12a. However, the lowest value of $\sum M, 14.57$, is obtained in $12 \mathrm{a}$, while in Fig. $12 \mathrm{~g} \sum M=15.11$. That means the best solution is obtained from Fig. 12a which shows the lowest value of $\sum M$. Overall, in Fig. 12a which represented 
the best feasible project schedule for problem given, the resources have been used efficiently in the first two days, while in the second three-days the resources utilization has been decreased by 1 unit, and in the remaining two days the resources utilization have been declined more to 1 unit. Thereby, MMORR can help the planners and schedulers to improve the resource utilization.

\section{Numerical Example}

A process plan identifies what resources are needed to perform the activities, and what operations and processes are necessary to use these resources to achieve the objectives of the project. To better understand the proposed model, an example of project network is given to present project activities on the node (AON) as depicted in Fig. 13, the project is constrained by precedence and resource constraints.

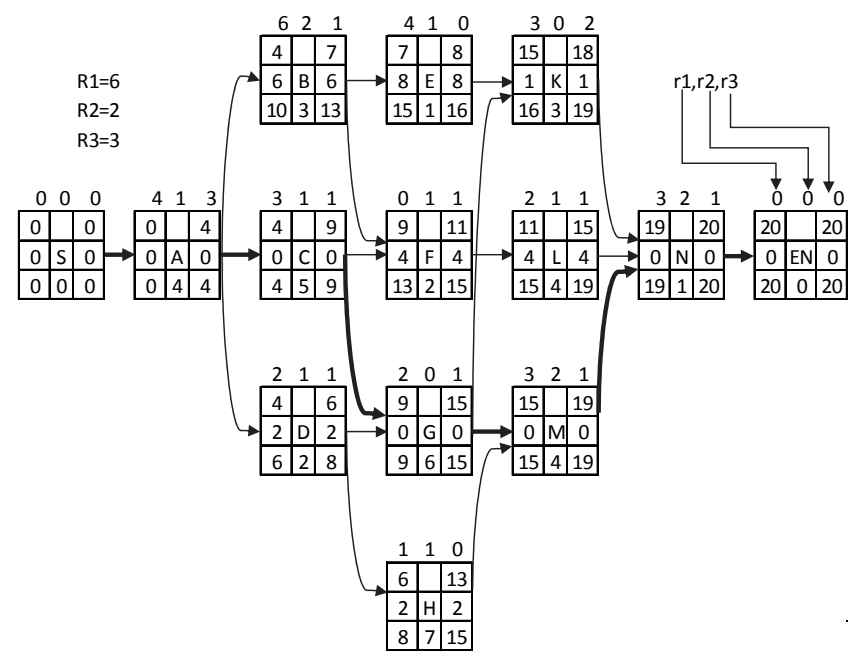

Fig. 13. Project network for the illustrative example

There are 14 activities, the first and the last ones are dummy. Three resource types are available 6, 2 and 3, and they must be allocated to the activities to complete the project as shown in Fig. 13.

From the perspective of the planners, the resources are usually allocated without considering the competition for the resources from other activities. Therefore, the generated process plans are somewhat unrealistic and cannot be easily executed on a group of activities. Accordingly, the resulting optimal process plans often become infeasible when they are carried out in practice at the later stage. In this example, the project completion time is 20 days, with resources requirements $R_{1}, R_{2}$ and $R_{3}$ are 11,4 and 3 respectively. Fig. 14. shows the project schedule with violations exists in the resources constraints as illustrated by the black circle for the $R_{1}, R_{2}$. The plan will pass to the second stage (scheduling phase). Scheduling is not only to sequence the planned activities, but also to determine the starting and completing times of each activity based on the sequence, which are illustrated in Fig. 14. Because the constraints imposed on the project, e.g. resource limitations, are not considered in the project planning, the project plan from planning phase may be infeasible due to the resource unavailable and activity completion time delays. Therefore, in this paper, we suggest project planning and scheduling should be carried out concurrently or integrated. The project planners and schedulers should work together to study the project plan and consider all constraints as mentioned before. They should try to find all possible alternative solutions to complete the project including the activities splitting by using the proposed model. Some of the possible project schedules, without considering activity splitting, are listed in Table 2. 

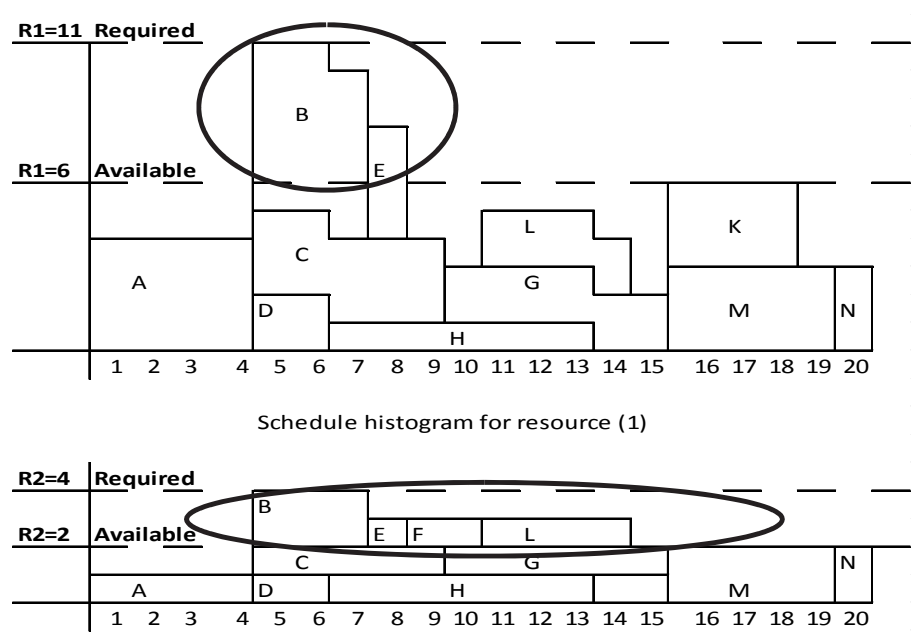

Schedule histogram for resource (2)

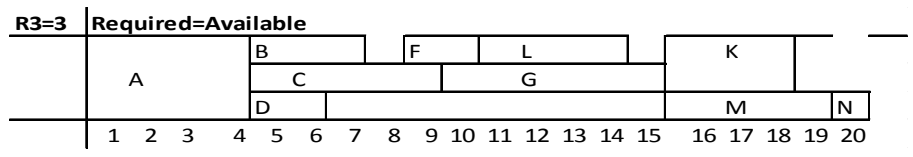

Schedule histogram for resource (3)

Fig. 14. Project schedule before resources leveling

\section{Table 2}

Feasible project schedule without activity splitting

\begin{tabular}{ccc}
\hline $\mathrm{N}$ & The activity sequences & Project duration \\
\hline 1 & A-D-C-H-B-E-F-G-L-K-M-N & 25 \\
2 & A-D-C-H-B-E-F-G-K-L-M-N & 24 \\
3 & A-D-C-H-B-E-F-G-L-M-K-N & 30 \\
4 & A-D-C-H-B-E-G-F-K-L-M-N & 27 \\
5 & A-D-C-H-G-B-E-F-K-M-L-N & 27 \\
6 & A-D-C-H-G-B-E-F-M-K-L-N & 27 \\
7 & A-D-C-H-G-B-F-E-L-K-M-N & 29 \\
8 & A-D-C-H-G-B-M-E-F-K-L-N & 31 \\
9 & A-D-C-H-G-M-B-E-K-F-L-N & 31 \\
10 & A-D-C-B-E-F-L-G-H-K-M-N & 25 \\
11 & A-B-D-E-C-H-F-G-L-K-M-N & 24 \\
\hline
\end{tabular}

By considering activity splitting, some of the possible project schedules are listed in Table 3.

\section{Table 3}

Feasible project schedule with activity splitting

\begin{tabular}{ccc}
\hline $\mathrm{N}$ & The activity sequences & Project duration \\
\hline 1 & A-C-D-B-C-H-E-G-F-H-L-K-M-N & 24 \\
2 & A-C-D-B-C-H-E-G-F-H-K-L-M-N & 24 \\
3 & A-C-D-B-C-H-E-F-G-H-L-K-M-N & 23 \\
\hline
\end{tabular}

The last project schedule, in Table 3, which has project duration $=23$, is the best one among the alternatives because of the activities splitting. Fig. 15 illustrates the sequences of activities and the project duration after resources leveling and limitation checking. 


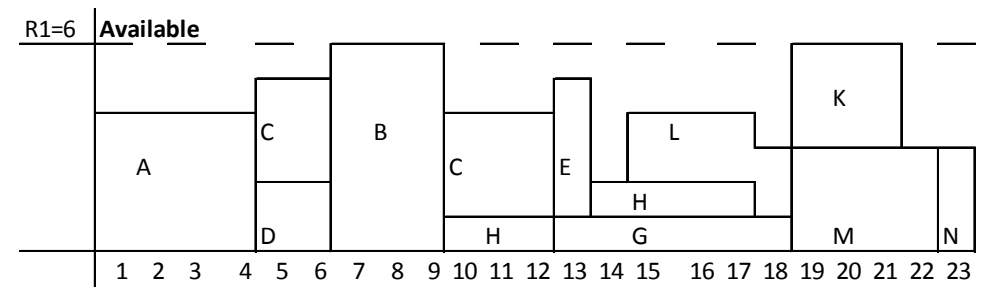

Schedule histogram for resource (1) after resource leveling

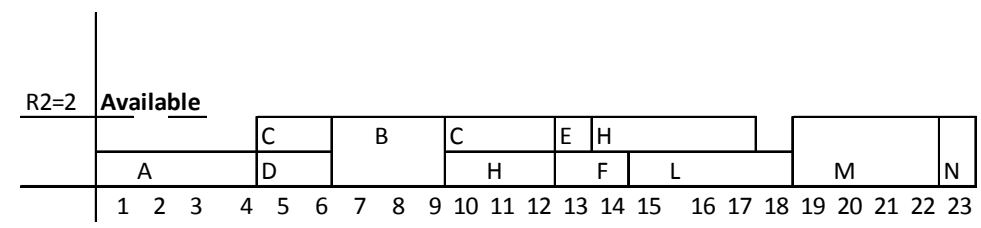

Schedule histogram for resource (2) after resource leveling

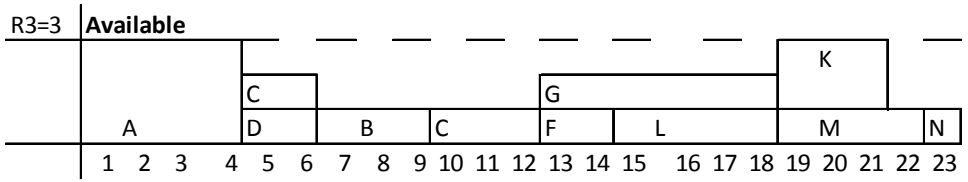

Schedule histogram for resource (3) after resource leveling

Fig. 15. Project schedule after resources leveling and limitation checking (activity splitting is allowed)

From Fig. 15 it shows that there is an improvement in project completion time by activities splitting occurred in activities $\mathrm{C} \& \mathrm{H}$ as depicted in Table 3, in comparison with the other solutions when activities splitting is not allowed as indicated in Table 2. To observe Tables 2 and 3 and Fig. 15, it is obvious that the project schedule with completion time of 23 is the best one.

\section{Table 4}

The value of the objective function

\begin{tabular}{ccccccc}
\hline & \multicolumn{2}{c}{ Branch and Bound (MMORR) } & & \\
\hline Resource type & Description & $\begin{array}{c}\text { Maximum Resource } \\
\text { available }\end{array}$ & $\begin{array}{c}\text { Resource available. } \\
\text { days }\end{array}$ & $\begin{array}{c}\text { Resource used. } \\
\text { days }\end{array}$ & $\begin{array}{c}\text { Resource utiliza- } \\
\text { tion\%. days }\end{array}$ & $\sum M$ \\
\hline 1 & R1 & 6 & $6 * 23=138$ & 108 & $78 \%$ & 213.3 \\
2 & R2 & 2 & $2 * 23=46$ & 41 & $89 \%$ & 242.6 \\
3 & R3 & 3 & $3 * 23=69$ & 45 & $65 \%$ & 157.1 \\
\hline
\end{tabular}

As illustrated in Table 4, the value of the objective function is 613, the percentage of resource utilization for R3 is $65 \%$, which is lower than the other resource utilizations. This implies that a utilization improvement of this resource may be achievable if it works independently as depicted in Fig. 16.

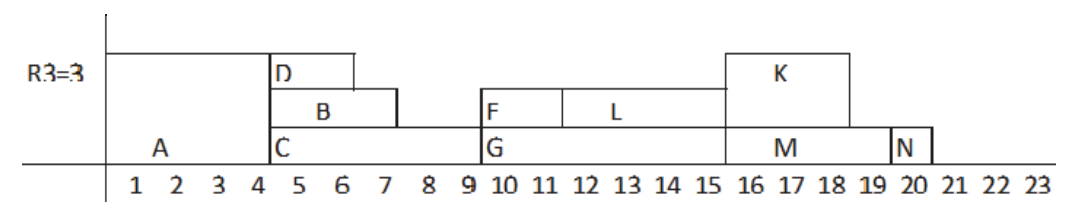

Fig. 16. Improvement in resource utilization for R3 
Table 5 illustrates the effectiveness of changing the resource R3 on the value of the objective function, when the resource works independently from the other two resources, and the value of objective function for the project schedule after the improving the utilization of R3 is 584.8. This indicates that the schedule becomes better than the previous one.

Table 5

The value of the objective function after improving the utilization in R3

\begin{tabular}{ccccccc}
\hline & \multicolumn{2}{c}{ Branch and Bound (MMORR) } \\
\hline Resource type & description & $\begin{array}{c}\text { Maximum Resource } \\
\text { available }\end{array}$ & $\begin{array}{c}\text { Resource available. } \\
\text { days }\end{array}$ & $\begin{array}{c}\text { Resource used. } \\
\text { days }\end{array}$ & $\begin{array}{c}\text { Resource utiliza- } \\
\text { tion\%. days }\end{array}$ & $\sum M$ \\
\hline 1 & R1 & 6 & $6^{*} 23=138$ & 108 & $78 \%$ & 213.3 \\
2 & R2 & 2 & $2 * 23=46$ & 41 & $89 \%$ & 242.6 \\
3 & R3 & 3 & $3 * 20=60$ & 45 & $75 \%$ & 128.9 \\
\hline
\end{tabular}

As demonstrated in this example, it is worth to note that keeping open communication channels among all involved parties especially planning and scheduling departments, and disseminating appropriate and timely information are extremely important to improve project planning and scheduling feasibility as well as the project resource utilization or shortening the project duration.

\section{Result analysis and discussion}

In this paper, a case study for multi-resources constrained project scheduling problem has been solved by (Shanmuganayagam, 1989, 0733-9364/89/0003-0401) using Current Float Techniques for resources scheduling. We apply our model to solve the same problem, and compare and contrast the two results in Table 6. The project duration by using the current float method without considering the resource limitation is 32 days, and the project duration being extended by 8 days to 40 days when the resources limitation is imposed. By using the proposed model, without considering the resources limitation, the project duration is 32 days. However, the project duration being extended by 6 days to 38 days, when the resources limitation is imposed and splitting activity is allowed. In addition, there is an improvement in the resources utilization by $4 \%$.

The improvement has been occurred in the objective function by using the new criterion, MMORR. It can be seen from Table 6 that the Minimum Moments of Resources Required around the axes are 1670 by using the current float technique and 1575 by using our model. Table 7 , illustrates an improvement in Machine B, i.e. 13\% - 4\% =9\%. This suggests that Machine B can finish its tasks in the project in 34 days instead of 38 days if it works independently. The minimum moment of the resources required around axes for the project decreased from 1575 to 1435 .

Table 6

Comparison between Current Float Tech. and the new model B \& B (MMORR)

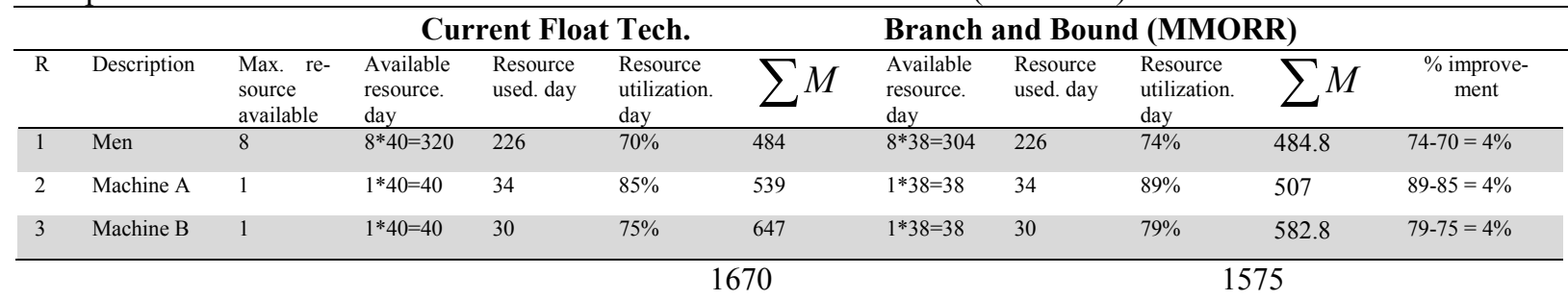


Table 7

Comparison between current Float Tech. and the new model B \& B (MMORR) after improving R3

\begin{tabular}{|c|c|c|c|c|c|c|c|c|c|c|c|}
\hline \multicolumn{7}{|c|}{ Current float tech. } & \multicolumn{5}{|c|}{ Branch and Bound (MMORR) } \\
\hline $\mathrm{R}$ & Description & $\begin{array}{l}\text { Max. re- } \\
\text { source } \\
\text { available }\end{array}$ & $\begin{array}{l}\text { Available } \\
\text { resource. } \\
\text { day }\end{array}$ & $\begin{array}{l}\text { Resource } \\
\text { used. day }\end{array}$ & $\begin{array}{l}\text { Resource } \\
\text { utilization. } \\
\text { day }\end{array}$ & & $\begin{array}{l}\text { Available } \\
\text { resource. } \\
\text { day }\end{array}$ & $\begin{array}{l}\text { Resource } \\
\text { used. day }\end{array}$ & $\begin{array}{l}\text { Resource } \\
\text { utilization. } \\
\text { day }\end{array}$ & $\sum M$ & $\begin{array}{l}\text { \% improve- } \\
\text { ment }\end{array}$ \\
\hline 1 & Men & 8 & $8 * 40=320$ & 226 & $70 \%$ & 484 & $8 * 38=304$ & 226 & $74 \%$ & 484.8 & $74-70=4 \%$ \\
\hline 2 & Machine A & 1 & $1 * 40=40$ & 34 & $85 \%$ & 539 & $1 * 38=38$ & 34 & $89 \%$ & 507 & $89-85=4 \%$ \\
\hline 3 & Machine B & 1 & $1 * 40=40$ & 30 & $75 \%$ & 647 & $1 * 34=34$ & 30 & $88 \%$ & 443 & $88-75=13 \%$ \\
\hline & & & & & & & & & & & \\
\hline
\end{tabular}

\section{Conclusion}

Integrated planning and scheduling processes are two important decision-making processes, which aim at gaining high utilization of resources and improving the efficiency of the project through the project life cycle. In this paper, by using Branch and Bound method, Minimum Moment of Resources Required around the axes as an evaluation criterion, and considering the activities splitting as a way to shorten the project duration, we present a novel approach for integrated planning and scheduling projects under multi-resource constraints. The results demonstrate that the presented approach can effectively improve the average utilization of various resources and shorten the project duration. Particularly, in comparison with the existing methods, it gives better results.

\section{References}

Ahuja, H. N. (1976). Construction performance control by networks. New York; Toronto: Wiley.

Akpan, E. O. (2000). Resource smoothing: A cost minimization approach. Production Planning \& Control, 11(8), 775-780.

Bandelloni, M., Tucci, M., \& Rinaldi, R. (1994). Optimal resource leveling using non-serial dyanamic programming. European Journal of Operational Research, 78(2), 162-177.

Bell, C. E., \& Park, K. (1990). Solving resource-constrained project scheduling problems by a* search. Naval Research Logistics (NRL), 37(1), 61-84.

Burgess, A. R., \& Killebrew, J. B. (1962). Variation in activity level on a cyclical arrow diagram. Journal of Industrial Engineering, 13(2), 76-83.

Burns, S. A., Liu, L., \& Feng, C. W. (1996). The LP/IP hybrid method for construction time-cost tradeoff analysis. Construction Management \& Economics, 14(3), 265-276.

Chan, W. T., Chua, D. K., \& Kannan, G. (1996). Construction resource scheduling with genetic algorithms. Journal of Construction Engineering and Management, 122(2), 125-132.

Christodoulou, S. E., Ellinas, G., \& Michaelidou-Kamenou, A. (2009). Minimum moment method for resource leveling using entropy maximization. Journal of Construction Engineering and Management, 136(5), 518-527.

Chua, D. K. H., Chan, W. T., \& Kannan, G. (1996). Scheduling with co-evolving resource availability profiles. Civil Engineering Systems, 13(4), 311-329.

Easa, S. M. (1989). Resource leveling in construction by optimization. Journal of construction engineering and management, 115(2), 302-316.

Elmaghraby, S. E. (1993). Resource allocation via dynamic programming in activity networks. European Journal of Operational Research, 64(2), 199-215.

El-Rayes, K., \& Jun, D. H. (2009). Optimizing resource leveling in construction projects. Journal of Construction Engineering and Management, 135(11), 1172-1180.

Feng, C. W., Liu, L., \& Burns, S. A. (1997). Using genetic algorithms to solve construction time-cost trade-off problems. Journal of Computing in Civil Engineering, 11(3), 184-189. 
Gagnon, M. (2004). A tabu search algorithm for the resource constrained project scheduling problem. In In Proceedings of Administrative Sciences Association of Canada Annual Conference (ASAC).

Harris, R. (1978). Resource and arrow networking techniques for construction.

Hariga, M., \& El-Sayegh, S. M. (2010). Cost optimization model for the multiresource leveling problem with allowed activity splitting. Journal of Construction Engineering and Management, 137(1), 56-64.

Hegazy, T. (1999). Optimization of resource allocation and leveling using genetic algorithms. Journal of Construction Engineering and Management, 125(3), 167-175.

Hiyassat, M. A. S. (2000). Modification of minimum moment approach in resource leveling. Journal of Construction Engineering and Management, 126(4), 278-284.

Hiyassat, M. A. S. (2001). Applying modified minimum moment method to multiple resource leveling. Journal of Construction Engineering and Management, 127(3), 192-198.

Hossein Hashemi Doulabi, S., Seifi, A., \& Shariat, S. Y. (2010). Efficient hybrid genetic algorithm for resource leveling via activity splitting. Journal of Construction Engineering and Management, 137(2), 137-146.

Karaa, F. A., \& Nasr, A. Y. (1986). Resource management in construction. Journal of Construction Engineering and Management, 112(3), 346-357.

Lee, H., \& Kim, S. S. (2001). Integration of process planning and scheduling using simulation based genetic algorithms. The International Journal of Advanced Manufacturing Technology, 18(8), 586590.

Mattila, K. G., \& Abraham, D. M. (1998). Resource leveling of linear schedules using integer linear programming. Journal of Construction Engineering and Management, 124(3), 232-244.

Myers, K. L., \& Smith, S. F. (1999, November). Issues in the integration of planning and scheduling for enterprise control. In Proc. DARPA Symposium on Advances in Enterprise Control.

Senouci, A. B., \& Adeli, H. (2001). Resource scheduling using neural dynamics model of Adeli and Park. Journal of Construction Engineering and Management, 127(1), 28-34.

Senouci, A. B., \& Eldin, N. N. (2004). Use of genetic algorithms in resource scheduling of construction projects. Journal of Construction Engineering and Management, 130(6), 869-877.

Shanmuganayagam, V. (1989). Current float techniques for resources scheduling. Journal of Construction Engineering and Management, 115(3), 401-411.

Son, J., \& Mattila, K. G. (2004). Binary resource leveling model: Activity splitting allowed. Journal of Construction Engineering and Mmanagement, 130(6), 887-894.

Son, J., \& Skibniewski, M. J. (1999). Multiheuristic approach for resource leveling problem in construction engineering: Hybrid approach. Journal of Construction Engineering and Management, 125(1), 23-31.

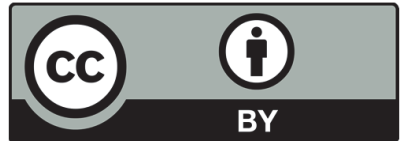

(C) 2017 by the authors; licensee Growing Science, Canada. This is an open access article distributed under the terms and conditions of the Creative Commons Attribution (CC-BY) license (http://creativecommons.org/licenses/by/4.0/). 